\title{
Silicon improves the emergence and sanity of rice seedlings obtained from seeds infected with Bipolaris oryzae
}

\author{
Leandro J. Dallagnol'1, Fabrício A. Rodrigues² \& Matheus V. B. Mielli² \\ ${ }^{1}$ Departamento de Fitossanidade, Faculdade de Agronomia Eliseu Maciel, Universidade Federal de Pelotas, 96010-900, \\ Pelotas, RS, Brazil; ${ }^{2}$ Departamento de Fitopatologia, Universidade Federal de Viçosa, 36570-000, Viçosa, MG, Brazil
}

Author for correspondence: Fabrício A. Rodrigues, e-mail: fabricio@ufv.br

\begin{abstract}
This study investigated the importance of silicon ( $\mathrm{Si}$ ) in rice grain husk in association with fungicide treatment for preventing Bipolaris oryzae transmission from seed to seedling and the improvement in seedling emergence. Plants from cv. Oochikara and its mutant (lsil mutant) defective in active $\mathrm{Si}$ uptake were grown in nutrient solution without (-Si) or with (+Si) $\mathrm{Si}$ and their panicles were inoculated with $B$. oryzae. Seeds were evaluated for brown spot severity (BSS) and husk Si concentration. The Si concentration in the husks of cv. Oochikara plants was up to four times higher than the lsil mutant plants. BSS was significantly reduced in the husks of the seeds obtained from + Si plants, particularly for cv. Oochikara. A higher percentage of seedling emergence occurred for + Si plant seeds, particularly for cv. Oochikara, and a lower percentage of infected seedlings was observed for the + Si cv. Oochikara treatment, particularly for the fungicide treated seeds. Fungicide was not efficient in preventing seedling infection by $B$. oryzae for seeds with BSS greater than $50 \%$. High Si concentration in the husk resulted in lower BSS and the fungicide efficiency was greater with a low BSS on seeds from + Si plants, particularly for cv. Oochikara.
\end{abstract}

Key words: disease control, mineral nutrition, seed pathology, soilborne pathogen.

\section{INTRODUCTION}

The fungus Bipolaris oryzae (Breda de Haan) Shoemaker [anamorph: Cochliobolus miyabeanus (Ito \& Kuribayashi) Drechsler] causes different diseases in rice (Oryza sativa L.) such as leaf brown spot, grain brown spot and seedling death (Ou, 1985; Lee, 1992). The damage caused by this pathogen with regard to yield is associated with the disease incidence on the leaves and grains (Lee, 1992). The occurrence of brown spot on leaves affect grain production by decreasing the number and the grains weigh per panicle (Prabhu et al., 1980; Aluko, 1975). Rice seeds infected by $B$. oryzae will generate kernel discoloration reducing the yield of intact kernels after the milling process (Marchetti \& Petersen, 1984; Soave et al., 1984).

The fungus $B$. oryzae can survive in crop debris and alternative hosts, but seed infection is the main survival strategy, extending up to four years, and is the most efficient route of long-distance pathogen dissemination and serving as the initial inoculum for leaf brown spot epidemics $(\mathrm{Ou}$, 1985; Lee, 1992). When infected seeds are used for sowing, the dormant mycelium infecting the seed is reactivated during germination, causing lesions on roots, coleoptiles and primary leaves and in some severe infections causes seedling death (Nyvall, 1989; Nghiep \& Gau, 2004). The transmission rate of $B$. oryzae from seed to seedling may reach up to $80 \%$ (Toledo et al., 2006). Therefore, utilizing sanity seeds is an important measure to reduce the yield damage caused by $B$. oryzae. Healthy seeds can be obtained by reducing grain infection during seed field production. Moreover, the transmission of the pathogen from seed to seedling can be prevented by treating the seeds with fungicide (Ou, 1985).

Rice is the most effective silicon ( $\mathrm{Si}$ ) accumulating plant known and accumulates Si to levels up to $10.0 \%$ of shoot dry weight (Ma et al., 2002; Dallagnol et al., 2009). Therefore, high Si content of the shoot is considered to be important for the healthy growth of rice and for stability of rice production. Accumulation of $\mathrm{Si}$ in the plant tissues helps to alleviate water stress, improves light interception, increases resistance to pests and lodging, remediates nutrient imbalances and several other beneficial effects (Savant et al., 1997; Epstein, 1999). The most known benefit is regarding the reduction in the intensity of several diseases in many plant species (Datnoff et al., 2007). Supplying Si to rice plants proved to be a viable method to reduce the severity of many diseases such as blast, brown spot, leaf blight, leaf scald, sheath blight and stem rot (Datnoff et al., 2007; Dallagnol et al., 2009). Because rice plants requires a high amount of Si for a high yield and to increase their resistance against diseases, the lsil mutant, which is impaired in active Si uptake mediated by the Lsil transporter gene, exhibits a greatly susceptibility to brown spot (Dallagnol et al., 2009, 2011). Similar to the observed impairment in the resistance to brown spot on leaves (Dallagnol et al., 2009, 2011), the grains obtained from lsil mutant plants show a high 
brown spot severity on the husks (Ma et al., 2002, 2006). In addition, Prabhu et al. (2012) showed reduction in rice grain discoloration for several rice genotypes under upland condition due to Si amendment.

Based on these findings, this study evaluated the effect of Si supplementation in rice plants intended for seed production and the importance of active Si uptake for healthy seeds. The seedlings emergence and $B$. oryzae transmission from seeds to seedlings were evaluated for seeds produced in plants of cv. Oochikara and its lsil mutant supplied and not supplied with Si. The combined effect of Si supply to plants intended for seed production and seed treatment with fungicide prior to sowing was also evaluated.

\section{MATERIAL AND METHODS}

\section{Seed material used to study B. oryzae transmission from seed to seedling}

The seeds used in the present study were obtained from rice cv. Oochikara and $l s i 1$ mutant (originated from cv. Oochikara) plants grown in nutrient solution without (-Si) or with $(+\mathrm{Si} ; 2 \mathrm{mM}) \mathrm{Si}$, as previously described by Dallagnol et al. (2011). The plants were grown in a greenhouse with a relative humidity of $60 \pm 5 \%$, temperature of $30 \pm 5^{\circ} \mathrm{C}$ and photon flux density of approximately $900 \mu$ mol photons $\mathrm{m}^{-2}$ $\mathrm{s}^{-1}$. At the beginning of the milk grain stage (IRRI, 1996), the panicles of each plant were inoculated with a conidial suspension $\left(5 \times 10^{3}\right.$ conidia $\left.\mathrm{mL}^{-1}\right)$ of $B$. oryzae. The fungus B. oryzae (CNPAF-HO 82, obtained from symptomatic rice plants and provided by Dr. Anne Sitarama Prabhu, EMBRAPA Arroz e Feijão, Goiânia, Brazil), was grown in potato-dextrose-agar medium at $25^{\circ} \mathrm{C}$ with a $12-\mathrm{h}$ photoperiod for 10 days. A conidial suspension was applied as a fine mist to the panicles of each plant until runoff using a VL Airbrush atomizer (Paasche Airbrush Co.). After inoculation the rice plants were incubated for $72 \mathrm{~h}$ ( $24 \mathrm{~h}$ of dark, followed by a $12-\mathrm{h}$ photoperiod) at $25 \pm 2^{\circ} \mathrm{C}$ and $90 \pm 5 \%$ relative humidity. After this period, the plants were transferred to greenhouse. The panicles were handharvested at the stage of physiological maturity (IRRI, 1996), 40 days after inoculation. The brown spot severity on the grains obtained from each panicle per plant was scored using a scale of 0 to 7 from IRRI (1996), with the following modifications: $0=$ no disease symptoms, $1=$ less than $1 \%$, $2=$ from 1.1 to $5 \%, 3=$ from 5.1 to $10 \%, 4=$ from 10.1 to $25 \%, 5=$ from 25.1 to $50 \%, 6=50.1$ to $75 \%$ and $7=$ more than $75 \%$ of the grain area showing disease symptoms. For the present study, the grains obtained from each plant were separated into classes 1 and 2, corresponding to grains that received scores of 0 to 5 and 6 and 7 , respectively.

\section{Determination of the husk Si concentration}

The grain husks were removed in a mill used for stripping, dried at $65^{\circ} \mathrm{C}$ for $72 \mathrm{~h}$ and ground with a ThomasWiley mill (Thomas Scientific) to pass through a 40-mesh screen. The Si concentration in the husks was determined by a colorimetric analysis using $0.1 \mathrm{~g}$ of dried and alkalidigested tissue (Dallagnol et al., 2011).

\section{Experimental design}

Two $2 \times 2 \times 2 \times 2$ factorial experiments consisting of the two Si rates ( 0 or $2 \mathrm{mM}$ ), plant materials (cv. Oochikara and lsi 1 mutant), classes 1 and 2 of brown spot severity and seeds treated or non-treated with fungicide were arranged in a completely randomized design with five replications. Each experimental unit consisted of one plastic tray containing fifty seedlings. The experiment was repeated once.

\section{Seed treatment with fungicide prior to sowing}

The grains harvested as described before were used as seeds for this experiment. The classes 1 and 2 from the cv. Oochikara and lsil mutant supplemented or not with Si were divided into two parts. Half of the seeds were treated with the fungicide Carbendazin $(150 \mathrm{~g} / \mathrm{L})+$ Thiram $(350 \mathrm{~g} / \mathrm{L})$ $(250 \mathrm{~mL}$ p.c $100 \mathrm{~kg}$ of seeds) before sowing. The fungicide was diluted in water $(1: 10)$ and immediately mixed with the seeds $(0.25 \mathrm{~mL}$ of solution $/ 10 \mathrm{~g}$ of seeds). After mixing, seeds were exposed to air for 3 hours for drying. The other half was treated with water to serve as the control treatment and processed as described for the fungicide treatment. The seeds of each treatment were sown in individual plastic trays $(50 \times 30 \times 8 \mathrm{~cm})$ containing $10 \mathrm{~kg}$ of sterilized sand $\left(120^{\circ} \mathrm{C}\right.$ for $2 \mathrm{~h}$ ) at a $1-\mathrm{cm}$ depth and $5 \mathrm{~cm}$ apart. After sowing and watering, the trays were kept inside a germination chamber during the experiment with a relative humidity of $75 \pm 5 \%$ and temperature of $22 \pm 2^{\circ} \mathrm{C}$.

\section{Assessments}

From seven to twenty-two days after sowing, the percentages of emerged seedlings and seedlings with brown spot symptoms were determined; the seedlings were considered emerged when the coleoptiles were $2 \mathrm{~cm}$ above the soil. The seedlings were considered infected when showed clear brown spot symptoms on the coleoptiles or primary leaves. Isolation of the causal agent of the observed symptoms was performed to confirm the presence of $B$. oryzae. At the end of experiments, at 22 days after sowing, the seedlings were collected, dried at $65^{\circ} \mathrm{C}$ for $72 \mathrm{~h}$ and weighed to determine the dry matter content.

\section{Data analysis}

Data from the two experiments were pooled for analysis based on Cochran' test for homogeneity of variance. Data were analyzed by analysis of variance and treatment mean comparisons by Student's test $(P \leq 0.05)$ using SAS version 8.0 (SAS Institute, Inc.).

\section{RESULTS}

\section{Grain brown spot severity}

The grain brown spot severity was reduced when the plants were supplemented with Si (+Si plants, Fig. 1). 
For the $+\mathrm{Si}$ cv. Oochikara treatment, a high percentage $(79.8 \%)$ of symptomatic grains showed severity less than $10 \%$ and was rated with a score of 2 , followed by scores of 1 and 3 (Figure 1A); only $1.3 \%$ of grains were rated with a score of 6 . In contrast, the grain from lsil mutant plants supplemented with Si were rated with all scores, showing an increase in the percentage of grains with a severity greater than $10 \%$ (Figure 1B), and a high percentage (75.7\%) of symptomatic grains were rated with scores of 1 to 4 . With regard to the grains from the $+\mathrm{Si}$ treatment, a significantly high percentage of scores 1 and 2 and a significantly low percentage of scores 5,6 and 7 were found for the cv. Oochikara compared to the lsil mutant (Figure 1). Conversely, no significant difference in brown spot severity was observed between cv. Oochikara and the lsil mutant grains from the -Si treatment. A high percentage of symptomatic grains from the -Si cv. Oochikara and -Si lsil mutant treatments (97 and 93\%, respectively) were rated with scores 5 to 7 ; none of the grains were rated with a score of 0 , and only few grains received scores 1 to $3(0.9$ and $2 \%$ for cv. Oochikara and the $l s i 1$ mutant, respectively). For the $+\mathrm{Si}$ cv. Oochikara treatment, the grains were ranked into classes 1 and 2 at 98.7 and $1.3 \%$, respectively, whereas 89 and $11 \%$ of the + Si $l$ si 1 mutant treatment grains were ranked into classes 1 and 2, respectively. For the $-\mathrm{Si} \mathrm{cv}$. Oochikara and -Si lsil mutant treatments, 12.7 and $23.6 \%$ of the grains were ranked into class 1, respectively, and 87.3 and $76.4 \%$, respectively, were ranked into class 2 .

\section{Concentration of $\mathrm{Si}$ in the husks}

The factors of $\mathrm{Si}$ rate, plant materials and the interaction of both factors were statistically significant (data not shown). The Si concentration was significantly greater, by 506 and $178 \%$, for the husks of grains from cv. Oochikara and the lsil mutant plants, respectively, supplied with Si compared to the husks of grains from the -Si plants of both plant materials (Table 1). The husks from grains of cv. Oochikara contained a significantly higher (240 and 56\% for the $+\mathrm{Si}$ and $-\mathrm{Si}$ plants, respectively) Si concentration compared to the lsil mutant.

\section{Seedling emergence, B. oryzae transmissibility and seedling dry matter}

The factors of Si rates, plant materials, seed class and seed treatment with or without fungicide and some interactions were significant for the percentage of emerged seedlings, percentage of infected seedlings and seedling dry matter (data not shown). The percentage of emerged seedlings increased by 106 and $92 \%$ for the seeds from $\mathrm{cv}$. Oochikara and the lsil mutant, respectively, supplied with $\mathrm{Si}$ compared to the plants not supplied with $\mathrm{Si}$ (Table 2). Comparing the plant materials, the percentage of emerged seedlings for $\mathrm{cv}$. Oochikara was significantly higher for the $-\mathrm{Si}$ and $+\mathrm{Si}$ treatments, by 38 and $48 \%$, respectively, compared to the lsil mutant. The percentage of emerged seedlings increased by 123 and $74 \%$ for the seeds of class 1 and class 2, respectively, obtained from the + Si plants compared to the -Si plants. Comparing the seed classes, the percentage of emerged $+\mathrm{Si}$ seedlings for class 1 was significantly higher (by $48 \%$ ) compared to class 2 ; no significant difference occurred between the seed classes for the -Si treatment. The fungicide treatment increased the percentage of emerged seedlings by $27 \%$ for the seeds obtained from $+\mathrm{Si}$ plants compared to non-treated seeds. However, no significant difference was found between the non-treated and fungicide-treated seeds for the -Si
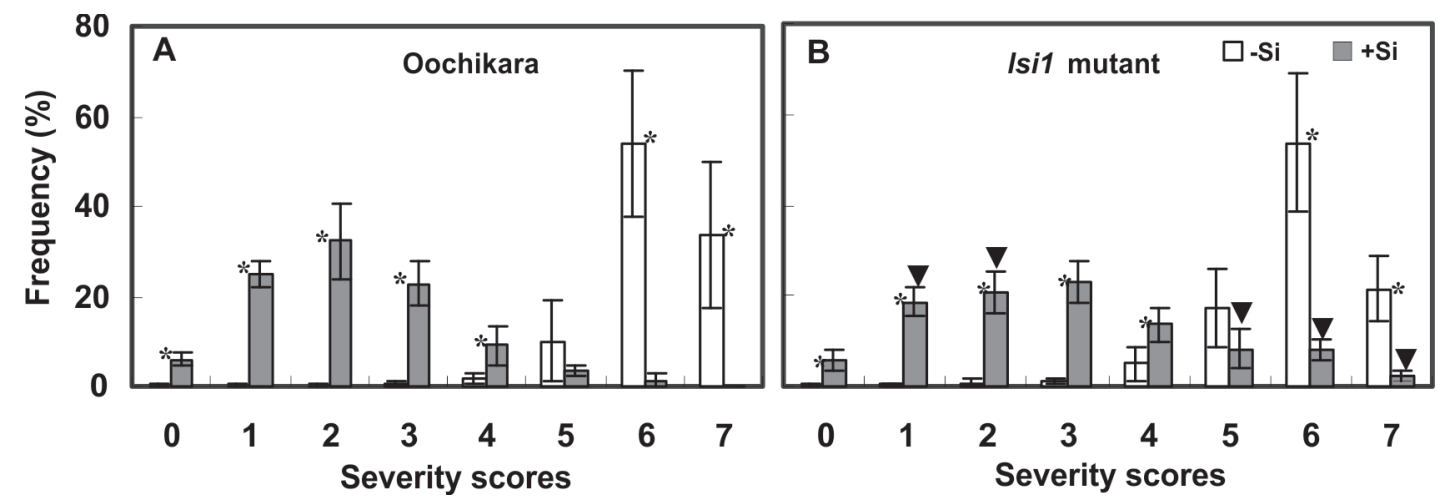

FIGURE 1 - Frequency of brown spot severity scores for rice grains obtained from the panicles of plants from cv. 'Oochikara' (A) and lsil mutant $(\mathbf{B})$ grown in a hydroponic culture containing $0(-\mathrm{Si})$ or $2(+\mathrm{Si}) \mathrm{mM}$ silicon $(\mathrm{Si})$ and inoculated with Bipolaris oryzae. Means for each plant material from the -Si and +Si treatments followed by an asterisk $\left(^{*}\right)$ are significantly different $(P \leq 0.05)$ by $t$-test. Means from the $l s i 1$ mutant for $-\mathrm{Si}$ and $+\mathrm{Si}$ treatments followed by an inverted triangle $(\boldsymbol{\nabla})$ are significantly different $(P \leq 0.05)$ from the respective treatment from cv. 'Oochikara' by $t$-test. $(n=10)$. The values of severity scores represent: $0=$ no disease symptoms, $1=$ less than $1 \%$, $2=$ from 1.1 to $5 \%, 3=$ from 5.1 to $10 \%, 4=$ from 10.1 to $25 \%, 5=$ from 25.1 to $50 \%, 6=50.1$ to $75 \%$ and $7=$ more than $75 \%$ of the grain area showing brown spot symptoms. 
TABLE 1 - Silicon (Si) concentration in the husk of rice grains obtained from plants of cultivar Oochikara and lsil mutant grown in hydroponic culture amended with $0(-\mathrm{Si})$ or $2(+\mathrm{Si}) \mathrm{mM}$ of $\mathrm{Si}$

\begin{tabular}{lccc}
\hline \hline \multirow{2}{*}{ Treatments } & \multicolumn{3}{c}{ Si $\left(\mathbf{d a g ~ \mathbf { ~ k g } ^ { - 1 } )}\right.$} \\
\cline { 2 - 4 } & $\mathbf{- S i}$ & $+\mathbf{S i}$ & $\boldsymbol{P}$ values \\
\hline Oochikara & 0.50 & 3.03 & 0.0001 \\
lsil mutant & 0.32 & 0.89 & 0.0002 \\
$P$ values & 0.043 & 0.0001 & \\
\hline
\end{tabular}

The factor interaction effects were sliced and means compared by $F$-test. Data showed are from two pooled experiments. $n=10$.

treatment (Table 2). Comparing the Si rates, the percentage of emerged seedlings for the +Si treatment was significantly higher for non-treated and treated seeds, by 77 and 123\%, respectively, compared to the -Si treatment (Table 2).

The percentage of infected seedlings was reduced by 47 and $50 \%$ for the seeds from cv. Oochikara and the lsil mutant plants, respectively, supplied with Si compared to the plants not supplied with Si (Table 3). Comparing the plant materials, the percentage of infected cv. Oochikara seedlings was significantly lower (by $18 \%$ ) for the $-\mathrm{Si}$ treatment when compared to the lsil mutant seedlings. No significant difference occurred between the plant materials for the $+\mathrm{Si}$ treatment. With regard to the plant type, the fungicide treatment reduced the percentage of infected seedlings by 50 and $17 \%$ for cv. Oochikara and the lsil mutant, respectively, compared to the non-treated seeds. No significant difference occurred between the plant materials for non-treated seeds, whereas the percentage of infected seedlings from treated seeds was 39\% lower for cv. Oochikara than for the lsil mutant (Table 3).

For the seeds from the -Si plants, the fungicide treatment reduced the percentage of infected seedlings by $38 \%$ for class 1 compared to the non-treated seeds (Table 4). Although no significant difference occurred between classes 1 and 2 for the non-treated seeds, the percentage of infected seedlings from the treated seeds was $43 \%$ lower for class 1 seeds than class 2 seeds. For the treated seeds from the $+\mathrm{Si}$ plants, the percentage of infected seedlings was reduced by 64 and $58 \%$, respectively, for class 1 and class 2 compared to the non-treated seeds. The percentage of infected seedlings was lower for class 1 for the treated and non-treated seeds, by 43 and 32\%, respectively, compared to class 2 . For the class 1 seeds, the percentage of infected seedlings was significantly lower for the $+\mathrm{Si}$ treatment (by 68 and 46\%) for the treated and non-treated seeds, respectively, compared to the seeds from the -Si plants. The percentage of infected seedlings from the class 2 seeds was significantly lower for the $+\mathrm{Si}$ treatment (by 68 and $20 \%$ ) for the non-treated and treated seeds, respectively, compared to the -Si treatment (Table 4).

The dry matter of the $+\mathrm{Si}$ plants increased by 62 and $34 \%$ for the treated and non-treated seeds, respectively, compared to the seeds from the -Si treatment (Table 5). No significant difference occurred between the non-treated and treated seeds for the -Si treatment, whereas the dry matter increased by $22 \%$ for the treated $+\mathrm{Si}$ seeds (Table 5 ).

For the treated cv. Oochikara seeds, the dry matter increased by $30 \%$ for the class 1 seeds compared to the nontreated seeds (Table 6). The seedling dry matter for the class 1 seeds was significantly higher, by 24 and $59 \%$, for the non-treated and treated seeds, respectively, compared to the

TABLE 2 - Emerged seedlings (\%) from rice seeds obtained from panicles of plants from cv. Oochikara and lsil mutant plants grown in a hydroponic culture containing $0(-\mathrm{Si})$ or $2(+\mathrm{Si}) \mathrm{mM}$ of silicon $(\mathrm{Si})$ and inoculated with Bipolaris oryzae. Seeds were classified into two classes (class 1 - less than $50 \%$ and class 2 - more than 50\%) of brown spot severity on husks and then treated $(+\mathrm{F})$ or non-treated $(-\mathrm{F})$ with fungicide before sowing

\begin{tabular}{|c|c|c|c|c|c|c|c|c|c|}
\hline \multirow[t]{2}{*}{ Treatments } & \multicolumn{3}{|c|}{ Plant materials } & \multicolumn{3}{|c|}{ Seeds classes } & \multicolumn{3}{|c|}{ Fungicide } \\
\hline & Oochikara & lsil mutant & $P$ values & 1 & 2 & $P$ & $+\mathbf{F}$ & $-F$ & $P$ values \\
\hline$-\mathrm{Si}$ & 35.63 & 25.75 & 0.0001 & 32.88 & 28.50 & 0.056 & 30.88 & 30.50 & 0.8764 \\
\hline$+\mathrm{Si}$ & 73.50 & 49.50 & 0.0001 & 73.50 & 49.50 & 0.0001 & 69.00 & 54.00 & 0.0001 \\
\hline$P$ values & 0.0001 & 0.0001 & & 0.0001 & 0.0001 & & 0.0001 & 0.0001 & \\
\hline
\end{tabular}

The factor interaction effects were sliced and means compared by $F$-test. Data showed are from two pooled experiments. $n=10$.

TABLE 3 - Infected seedlings (\%) from rice seeds obtained from panicles of plants from cv. Oochikara and lsil mutant plants grown in a hydroponic culture containing $0(-\mathrm{Si})$ or $2(+\mathrm{Si}) \mathrm{mM}$ of silicon $(\mathrm{Si})$ and inoculated with Bipolaris oryzae. Seeds were then treated $(+\mathrm{F})$ or non-treated (-F) with fungicide before sowing

\begin{tabular}{|c|c|c|c|c|c|c|}
\hline Treatments & $-\mathrm{Si}$ & $+\mathrm{Si}$ & $P$ values & $-F$ & $+\mathbf{F}$ & $P$ values \\
\hline Oochikara & 36.10 & 19.02 & 0.0001 & 36.97 & 18.15 & 0.0001 \\
\hline lsil mutant & 43.97 & 21.85 & 0.0001 & 35.90 & 29.92 & 0.0017 \\
\hline$P$ values & 0.0001 & 0.1256 & & 0.5582 & 0.0001 & \\
\hline
\end{tabular}

The factor interaction effects were sliced and means compared by $F$-test. Data showed are from two pooled experiments. $n=10$. 


\section{L.J. Dallagnol et al.}

TABLE 4 - Infected seedlings (\%) from rice seeds obtained from panicles of plants from cv. Oochikara and lsil mutant plants grown in a hydroponic culture containing $0(-\mathrm{Si})$ or $2(+\mathrm{Si}) \mathrm{mM}$ of silicon $(\mathrm{Si})$ and inoculated with Bipolaris oryzae. Seeds were classified into two classes of brown spot severity on husks: less than 50\% (class 1 ) and more than $50 \%$ (class 2 ) and then treated (+F) or non-treated (-F) with fungicide before sowing

\begin{tabular}{|c|c|c|c|c|c|c|}
\hline \multirow[t]{2}{*}{ Treatments } & \multicolumn{3}{|c|}{$-\mathrm{Si}$} & \multicolumn{3}{|c|}{$+\mathrm{Si}$} \\
\hline & Class 1 & Class 2 & $P$ values & Class 1 & Class 2 & $P$ values \\
\hline$-F$ & 43.50 & 43.60 & 0.9691 & 23.64 & 35.00 & 0.0001 \\
\hline$+\mathrm{F}$ & 26.64 & 46.40 & 0.0001 & 8.40 & 14.70 & 0.0172 \\
\hline$P$ values & 0.0001 & 0.2804 & & 0.0001 & 0.0001 & \\
\hline \multirow[t]{2}{*}{ Treatments } & \multicolumn{3}{|c|}{ Class 1} & \multicolumn{3}{|c|}{ Class 2} \\
\hline & $-\mathrm{Si}$ & $+\mathbf{S i}$ & $P$ values & $-\mathbf{S i}$ & $+\mathbf{S i}$ & $P$ values \\
\hline$-F$ & 43.50 & 23.64 & 0.0001 & 43.60 & 35.00 & 0.0014 \\
\hline$+\mathrm{F}$ & 26.64 & 8.40 & 0.0001 & 46.40 & 14.70 & 0.0001 \\
\hline
\end{tabular}

The factor interaction effects were sliced and means compared by $F$-test. Data showed are from two pooled experiments. $n=10$.

TABLE 5 - Dry matter (mg of 10 seedlings) of rice seedlings at 22 days after sowing seeds obtained from rice seeds from panicles of plants from cv. Oochikara and lsil mutant grown in a hydroponic culture containing $0(-\mathrm{Si})$ or $2(+\mathrm{Si}) \mathrm{mM}$ of silicon $(\mathrm{Si})$ and inoculated with Bipolaris oryzae. Seeds were treated (+F) or nontreated (-F) with fungicide before sowing

\begin{tabular}{lccc}
\hline \hline Treatments & $-\mathbf{S i}$ & $+\mathbf{S i}$ & $\boldsymbol{P}$ values \\
\hline$-\mathrm{F}$ & 0.085 & 0.114 & 0.0001 \\
$+\mathrm{F}$ & 0.086 & 0.139 & 0.0001 \\
\hline$P$ values & 0.8382 & 0.0006 & \\
\hline
\end{tabular}

The factor interaction effects were sliced and means compared by $F$-test. Data showed are from two pooled experiments. $n=10$.

class 2 seeds. No significant difference occurred between classes 1 and 2 for the treated lsi 1 mutant seeds, whereas the dry matter for class 1 was $35 \%$ higher than for class 2 for the treated seeds. No significant difference was found between the non-treated and treated seeds of class 1 , though the dry matter of seedlings from class 2 increased by $31 \%$ after fungicide treatment. For the class 1 seeds, the seedling dry matter was significantly higher for $\mathrm{cv}$. Oochikara (by 42 and $100 \%$ ) for the non-treated and treated seeds, respectively, compared to the $l s i l$ mutant. The dry matter of the seedlings from the class 2 seeds was significantly higher (by 56\%) for the non-treated cv. Oochikara seeds compared to the nontreated lsil mutant seeds (Table 6).

\section{DISCUSSION}

Seed quality is a key factor for the full exploitation of a crop in terms of yield and quality (McGee, 1995). Accordingly, the present study reports that supplying $\mathrm{Si}$ to rice plants and treating their seeds with fungicide can improve seedling emergence and dry matter and reduce the transmission of $B$. oryzae from seed to seedling. The rice seeds produced by plants supplied with $\mathrm{Si}$ showed a reduced severity of brown spot in the grains, particularly those obtained from cv. Oochikara for which the Si concentration in the husks was higher than in the lsil mutant. The cv. Oochikara plants supplied with Si showed a high proportion of seeds with a brown spot severity below $10 \%$. However, despite the lsil mutant plants being grown in the presence of $\mathrm{Si}$, the impairment in active $\mathrm{Si}$ transport from the roots to shoots most likely negatively affected the husk $B$. oryzae infection resistance conferred by $\mathrm{Si}$, resulting in increased damage to the seeds than that observed for cv. Oochikara. These results indicate that the Si-mediated increase in the resistance of rice grains to brown spot was strictly related to a functional Lsil gene, which is present in cv. Oochikara.

Although not determined in this study, the reduction on the brown spot severity may be associated to anticipation and increase in plant defense activation under pathogen attack caused by the presence of soluble $\mathrm{Si}$ in the plant tissue as previously proposed (Gareeb et al., 2011; Bockhaven et al., 2012). In rice leaves, Dallagnol et al. (2011) showed that Si activated earlier and stronger plant defense responses against $B$. oryzae, involving higher activity of chitinases and peroxidases, great concentration of phenolic compounds and lignin, lower lipid peroxidation and less electrolyte leakage.

It is known that $B$. oryzae is a seed-borne pathogen that reduces seedling emergence and development (Ou, 1985). However, the lower B. oryzae colonization of seed husks from the $+\mathrm{Si}$ plants, particularly for $\mathrm{cv}$. Oochikara, most likely reduced the fungal inoculum in the seeds, increasing seedling emergence and reducing the transmission of the fungus from seed to seedling.

Regarding seedling emergence, a higher percentage was obtained by sowing the seeds from cv. Oochikara plants supplied with Si. Furthermore, although the percentage of seedling emergence of the seeds from -Si plants was low and did not differ between the seed class or fungicide treatment, a higher number of emerged seedlings was found for the $+\mathrm{Si}$ plant seeds of class 1 and was enhanced by the fungicide treatment. For these seeds, the influence of Si may be associated with the limited and superficial colonization by 
TABLE 6 - Dry matter (mg of 10 seedlings) of rice seedlings at 22 days after sowing seeds obtained from panicles of cv. Oochikara and lsil mutant plants grown in a hydroponic culture containing $0(-\mathrm{Si})$ or $2(+\mathrm{Si}) \mathrm{mM}$ of silicon $(\mathrm{Si})$ and inoculated with Bipolaris oryzae. Seeds were classified into two classes of brown spot severity on husks: less than $50 \%$ (class 1 ) and more than $50 \%$ (class 2 ) and then treated $(+F)$ or non-treated (-F) with fungicide before sowing

\begin{tabular}{|c|c|c|c|c|c|c|}
\hline \multirow[t]{2}{*}{ Treatments } & \multicolumn{3}{|c|}{ Oochikara } & \multicolumn{3}{|c|}{ lsil mutant } \\
\hline & Class 1 & Class 2 & $P$ values & Class 1 & Class 2 & $P$ values \\
\hline$-F$ & 0.131 & 0.106 & 0.0134 & 0.092 & 0.068 & 0.0180 \\
\hline$+\mathrm{F}$ & 0.170 & 0.107 & 0.0001 & 0.085 & 0.089 & 0.6558 \\
\hline$P$ values & 0.0002 & 0.9499 & & 0.4584 & 0.0371 & \\
\hline \multirow[t]{2}{*}{ Treatments } & \multicolumn{3}{|c|}{ Class 1} & \multicolumn{3}{|c|}{ Class 2} \\
\hline & cv. Oochikara & lsil mutant & $P$ values & cv. Oochikara & lsil mutant & $P$ values \\
\hline$-\mathrm{F}$ & 0.131 & 0.092 & 0.0002 & 0106 & 0.068 & 0.0002 \\
\hline$+\mathrm{F}$ & 0.170 & 0.085 & 0.0001 & 0.107 & 0.089 & 0.0727 \\
\hline
\end{tabular}

The factor interaction effects were sliced and means compared by $F$-test. Data showed are from two pooled experiments. $n=10$.

the pathogen, which allowed better seed development. The contribution of the fungicide treatment may be associated with a reduction of the damage caused by $B$. oryzae in the sown seeds and in the seedlings. Furthermore, although $B$. oryzae localization in the seeds was not measured in the present study, the reduction in pathogen transmission from the $+\mathrm{Si}$ plant seeds may also be a result of reduced and superficial seed colonization by B. oryzae. This hypothesis is strengthened by the greater efficiency of fungicide treatment in preventing $B$. oryzae transmission to the seedlings originated from the seeds obtained from the $+\mathrm{Si}$ plants. According to Leach \& MacDonald (1976), pathogens superficially present on seeds are controlled more easily by fungicide treatment, thereby reducing seedling infection to a very low level.

In addition to the importance of $\mathrm{Si}$ in reducing the transmission of seed-borne pathogens from seed to seedling, the efficiency of the fungicide treatment was also lower for the seeds from -Si plants, with only $45 \%$ reduction in transmission in the seedlings originating from class 1 seeds. However, for the seeds from + Si plants, the fungicide treatment resulted in a higher reduction in the percentage of infected seedlings for both seed classes; in particular, the reduction reached up to $65 \%$ for the class 1 seeds. The importance of the Lsil gene in increasing the $\mathrm{Si}$ concentration in the husks and, consequently, reducing the transmission of $B$. oryzae from seed to seedling was highlighted by comparing the seeds of the plants treated with fungicide, showing a lower percentage of infected seedlings for cv. Oochikara than for the lsil mutant. These results showed that fungicide treatment can prevent $B$. oryzae transmission from seed to seedling, though the efficacy was dramatically improved when the plants were supplied with $\mathrm{Si}$, mainly because the defense against $B$. oryzae infection was potentiated, as previously reported by Dallagnol et al. (2011). A low efficacy of fungicide treatment was observed for the seeds from the -Si plants, with a higher seed brown spot severity, thus the fungicide treatment was not effective in preventing fungal infection in seedlings.
In addition to reducing the damage to seedlings, the decrease in $B$. oryzae transmission from seed to seedling for the $+\mathrm{Si}$ plants and fungicide treatment may also reduce fungal transmission to the aerial plant parts, most likely decreasing the production of conidia and preventing their dispersion to healthy plants by wind and rain under field conditions.

With regard to the dry matter, the seedlings originating from the seeds of $+\mathrm{Si}$ plants showed higher values, regardless of fungicide treatment. The importance of a higher Si concentration was highlighted by comparing the plant materials, with a higher dry matter being observed for the cv. Oochikara seedlings, which showed a higher Si concentration in the husk. This result does not indicate that Si present in the husk improved the dry matter but rather that the presence of $\mathrm{Si}$ in the husk may reduce the damage caused by $B$. oryzae to the seedling before fungicide treatment. Considering the effect of fungicide treatment on the seedling dry matter, the beneficial effect was more pronounced for the seedlings from the cv. Oochikara plants, indicating that combining a high Si concentration in the husks with seed fungicide treatment results in better seedling growth.

The importance of the Lsil gene for increasing the Si concentration in the rice husks and, consequently, conferring better physiological and sanity qualities to the seeds was demonstrated by the higher percentage of emerged seedlings, lower percentage of infected seedlings and higher seedling dry matter obtained from the seeds of cv. Oochikara plants supplied with Si. Furthermore, Si amendment to rice plants proved to be an important strategy to produce seeds with a higher sanity quality, a condition that increased the efficacy of fungicide treatment.

\section{ACKNOWLEDGEMENTS}

F.A. Rodrigues thanks Conselho Nacional de Desenvolvimento Científico e Tecnológico - CNPq for his fellowship. L.J. Dallagnol was supported by CAPES. 
This study was supported by grants from Coordenação de Aperfeiçoamento de Pessoal de Nível Superior - CAPES, $\mathrm{CNPq}$ and Fundação de Amparo à Pesquisa do Estado de Minas Gerais - FAPEMIG to F.A. Rodrigues.

\section{REFERENCES}

Aluko MO (1975) Crop losses caused by the brown leaf spot disease of rice in Nigeria. Plant Disease Reporter 59:609-613.

Bockhaven JV, De Vleesschauwer D, Höfte M (2012) Towards establishing broad-spectrum disease resistance in plants: silicon leads the way. Journal of Experimental Botany 64:1281-1293.

Dallagnol LJ, Rodrigues FA, Mielli MVB, Ma JF, Datnoff LE (2009) Defective active silicon uptake affects some components of rice resistance to brown spot. Phytopathology 99:116-121.

Dallagnol LJ, Rodrigues FA, DaMatta FM, Mielli MVB, Pereira SC (2011) Deficiency in silicon uptake affects cytological, physiological, and biochemical events in the rice-Bipolaris oryzae interaction. Phytopathology 101:92-104.

Datnoff LE, Rodrigues FA, Seebold KW (2007) Silicon and Plant Disease. In: Datnoff LE, Elmer WH, Huber DM (Eds.) Mineral Nutrition and Plant Disease. St. Paul MN, USA. APS Press. pp. 33-246.

Epstein E (1999) Silicon. Annual Review of Plant Physiology and Plant Molecular Biology 50:641-664.

Ghareeb H, Bozsó A, Ott PG, Repenning C, Stahl F, Wydra K (2011) Transcriptome of silicon-induced resistance against Ralstonia solanacearum in the silicon non-accumulator tomato implicates priming effect. Physiological and Molecular Plant Pathology 75:83-89.

IRRI (1996) Standard Evaluation System for Rice. $4^{\text {th }}$ Ed. Manila The Philippines. International Rice Research Institute.

Leach LD, MacDonald JD (1976) Seed-borne Phoma betae as influenced by area of sugar beet production, seed processing and fungicidal seed treatments. Journal of the American Society of Sugar Beet Technologists 19:4-15.

Lee FN (1992) Brown spot. In: Webster RK, Gunnell PS (Eds.)
Compendium of Rice Diseases. St. Paul MN, USA. APS Press. pp. 14-17.

Ma JF, Tamai K, Ichii M, Wu GF (2002) A rice mutant defective in Si uptake. Plant Physiology 130:2111-2117.

Ma JF, Tamai K, Yamaji N, Mitani N, Konishi S, Katsuhara M, Ishiguro M, Murata Y, Yano M (2006) A silicon transporter in rice. Nature 430:688-691.

Marchetti MA, Petersen HD (1984) The role of Bipolaris oryzae in floral abortion and kernel discoloration in rice. Plant Disease 68:288-291.

McGee DD (1995) Epidemiological approach to disease management through seed technology. Annual Review of Phytopathology 33:445-466.

Nghiep HV, Gaur A (2004) Role of Bipolaris oryzae in producing abnormal seedling of rice (Oryza sativa). Omonrice 12:102-108.

Nyvall RF (1989) Field Crop Diseases Handbook. New York NY, USA. Van Nostrand Reinhold.

Ou SH (1985) Rice Diseases. Kew UK. CMI/AAB.

Prabhu AS, Barbosa Filho MP, Datnoff LE, Snyder GH, Berni F, Rodrigues FA, Dallagnol LJ (2012) Silicon reduces brown spot severity and grain discoloration on several Rice genotypes. Tropical Plant Pathology 37:409-414.

Prabhu AS, Lopes AM, Zimmermann FJ (1980) Infecção da folha e do grão de arroz por Helminthosporium oryzae e seus efeitos sobre os componentes de produção. Pesquisa Agropecuária Brasileira 15:183-189.

Savant NK, Snyder GH, Datnoff LE (1997) Silicon management and sustainable rice production. Advances in Agronomy 58:151199.

Soave J, Pizzinatto MA, Usberti Junior JA, Camargo OBA, Villela OV (1984) Selection of rice cultivars resistant to some pathogens using seed health testing. Pesquisa Agropecuária Brasileira 19:449-453.

Toledo J, Rojas I, Aparicio L (2006) Transmisión y control de Bipolaris oryzae, Gelachia oryzae y Alternaria padwickii em semillas de arroz producidas en Santa Cruz, Bolivia. Fitopatologia Brasileira 31:S132. 